Pawel GROMEK

Szkoła Gtówna Stużby Pożarniczej ${ }^{1}$

Instytut Bezpieczeństwa Wewnętrznego

pgromek@sgsp.edu.pl

ORCID 0000-0003-0997-5069

https://doi.org/10.34739/dsd.2019.02.11

\title{
PROLEGOMENA DO BADAŃ KULTURY RATOWNICTWA
}

\begin{abstract}
ABSTRAKT: W artykule przedstawiono zarys zagadnienia kultury ratownictwa w Polsce. Kolejno, określono istoty przedmiotu badań, zbudowano i omówiono model idealny kultury ratownictwa w Polsce, a także scharakteryzowano jej ogólne uwarunkowania. Przyjętą hipotezę uprawdopodobniono $\mathrm{z}$ wykorzystaniem teoretycznych metod badawczych. Udowodniono, że model idealny kultury ratownictwa można zbudować na podstawie modelu kultury bezpieczeństwa Cieślarczyka, uwzględniając wszystkie dziedziny ratownictwa. Natomiast właściwe uwarunkowania mają swoje główne źródło w specyfice podmiotów ratownictwa. Są one wyrażane przez powszechnie przyjęte wartości, określone normy, eksponowane postawy i zachowania, a także realizowane działania (w tym współdziałanie w trybie pilnym).
\end{abstract}

SŁOWA KLUCzOWE: kultura, kultura ratownictwa, ratownictwo, bezpieczeństwo

\section{THE PROLEGOMENA TO RESEARCH OF THE RESCUE CULTURE IN POLAND}

\begin{abstract}
The paper presents an outline of the rescue culture in Poland. It was achieved by the specification of the research object, building and characterizing the ideal model of the rescue culture, as well as description of the general culture determinants. The hypothesis was acknowledged with the use of theoretical research methods. The author found out that the ideal model can be built on the base of the Cieślarczyk's security culture model, taking into consideration all areas of the rescue operations. Whereas relevant determinants have their main source in rescue entities specification. The determinants are expressed by commonly accepted values, established standards, expressed patterns and behaviors as well as conducted operations (including emergency cooperation).
\end{abstract}

KEYWORDS: culture, rescue culture, rescue, security

\footnotetext{
${ }^{1}$ The Main School of Fire Service; Poland.
} 


\section{WPROWADZENIE}

„Bezpieczeństwa nie widać. Widoczne są przeważnie przejawy jego braku”2. Z tego powodu badacze reprezentujący różne dyscypliny naukowe (zwłaszcza nauki o bezpieczeństwie i- mimo iż formalnie nie jest zlokalizowana na mapie polskiej nauki - inżynierię bezpieczeństwa) stają nierzadko przed wyzwaniem budowania i realizowania procesów poznawczych dotyczących trudno identyfikowalnych obiektów ontycznych i epistemologicznych. Niektóre z nich mogą występować jedynie w sferze konceptualnej, aczkolwiek cechować się potencjałem oddziaływania na realne składniki uniwersum bytowego. Wyrazem kształtowanej w ten sposób świadomości badawczej jest poruszanie przez naukowców zagadnień poczucia bezpieczeństwa (jako uzupełnienia pojęcia bezpieczeństwa eksperckiego), społecznego wzburzenia (współdeterminującego z ryzykiem obliczeniowym ryzyko w sensie ogólnym), odporności, podatności itp. ${ }^{3}$ Za szczególnie istotne dla rozwoju nauk społecznych uważa się powiązane z nimi pojęcie kultury bezpieczeństwa, również dającej wyraz temu, co niewidoczne, a mające wpływ na otaczającą rzeczywistość.

Koncepcje kultury bezpieczeństwa znajdują swoje zastosowanie w odniesieniu do zagadnień pozostających niejako na granicy teorii i praktyki przedmiotu poznania, zwłaszcza tam, gdzie odnotowuje się wyraźne niejednoznaczności, a nawet sprzeczności identyfikowalne w toku relatywizacji tych dwóch ujęć. Wielu wyraźnych przykładów można doszukać się w problematyce niezwłocznego niesienia pomocy ludziom, a także wybranym elementom środowiska i mieniu w zakresie niezbędnym do przeżycia ludności w wymiarach biologicznym i bytowo-kulturowym. Mowa o problematyce ratownictwa, której eksploracja naukowa prowadzi do wniosków ukazujących rozbieżności pomiędzy „tym, jak powinno być”, a „tym, jak jest”.

Wyniki realizacji I etapu pracy naukowo-badawczej pt. Projektowanie sieciowe doraźnych systemów ratownictwa $w$ Polsce ${ }^{4}$, potwierdzane ratowniczymi doświadczeniami własnymi autora niniejszej pracy oraz licznymi doniesieniami medialnymi, dowodzą potrzeby poznania charakteru i uwarunkowań ratownictwa w sferze jego kultury w celu zdobycia nowej wiedzy o m. in. społecznych czynnikach determinujących sprawność przedmiotowej działalności, a także powodach, dla których obywatele nie udzielają pomocy ratowniczej pomimo właściwych, prawnych obligacji. Pierwszym etapem mającym na celu uzupełnienie wykrytej luki wiedzy jest zbudowanie podstawowych założeń poznawczych dotyczących kultury ratownictwa w Polsce, co stanowi cel niniejszego artykułu. Związane jest również z postawieniem problemu badawczego pod postacią pytania: W jaki sposób przedstawić zagadnienie kultury ratownictwa w Polsce? Przyjęto, że może być to osiągnięte poprzez, kolejno, określenie istoty przedmiotu badań, zbudowanie i omówienie modelu idealnego kultury ratownictwa w Polsce, a także scharakteryzowanie jego ogólnych uwarunkowań.

\footnotetext{
${ }^{2}$ P. Gromek, Teoria organizacji bezpieczeństwa na przykładzie masowej ewakuacji ludności, Warszawa 2017, s. 124.

${ }^{3}$ Vide: J. Wolanin, Zarys teorii bezpieczeństwa obywateli. Ochrona ludności na czas pokoju, Warszawa 2005, s. 29-39.

${ }^{4}$ S/E-422/11/17, Szkoła Główna Służby Pożarniczej.
} 


\section{ISTOTA KULTURY RATOWNICTWA}

$\mathrm{Na}$ przestrzeni lat wielu teoretyków i praktyków podejmowało próby zdefiniowania ratownictwa. Należy tu wymienić m. in. autorów Małej encyklopedii wojskowej ${ }^{5}$, Słownika współczesnego języka polskiego ${ }^{6}$ oraz A. Skrabacz ${ }^{7}$ i Z. Zamiara ${ }^{8}$. Nie sposób pominąć przy tej okazji dokumentów prawnych, których treści precyzują, co formalnie należy rozumieć przez takie pojęcia jak ratownictwo górskie ${ }^{9}$, ratownictwo wodne ${ }^{10}$, działania ratownicze ${ }^{11}$, pierwsza pomoc i medyczne czynności ratunkowe ${ }^{12}$, akcja ratownicza ${ }^{13}$ czy też pomocnicze specjalistyczne czynności ratownicze ${ }^{14}$. Warto jednak nadmienić, że wzajemna relatywizacja wyrażanych $\mathrm{w}$ ten sposób definicji rzuca światło na wiele rozbieżności interpretacyjnych, które utrudniają jednoznaczne rozumienie tego, czym jest ratownictwo w swojej istocie ${ }^{15}$.

Autor wyraża przekonanie, że na ratownictwo należy patrzeć szeroko, wykraczając poza klasyczny sposób rozumienia sprowadzany do działalności formalnych systemów ratownictwa (np. krajowego systemu ratowniczo-gaśniczego, KSRG) czy też poszczególnych służb i straży (m. in. Państwowej Straży Pożarnej, PSP). Dlatego - czerpiąc z definicji formalnych oraz opracowań innych autorów - proponuje się definicję mówiącą o tym, że „ratownictwo to dziedzina bezpieczeństwa powszechnego oznaczająca działalność operacyjną na wszystkich poziomach zarządzania bezpieczeństwem państwa, we wszystkich stanach jego funkcjonowania, ukierunkowana na ochronę ludzi, a także mienia i środowiska w zakresie niezbędnym do ich przeżycia w wymiarach biologicznym i bytowo-kulturowym, w okolicznościach lub w związku z okolicznościami reagowania na zagrożenia w trybie niezwłocznym (natychmiastowym, pilnym)"16. Wynikają z niej zasadnicze kwestie cechujące ratownictwo jako kategorię pojęciową. Co istotne, podkreślono wpisywanie się go w zagadnienia dotyczące ochrony ludności i obrony cywilnej (poprzez relację z bezpieczeństwem powszechnym) ${ }^{17}$, pośrednio zaś bezpieczeństwo narodowe i bezpieczeństwo państwa.

Również pojęcie kultury bezpieczeństwa doczekało się wielu sposobów rozumienia. Zdaje się być na tyle uniwersalne, że można je odnosić do bezpieczeństwa narodowego

\footnotetext{
${ }^{5}$ Mała encyklopedia wojskowa, t. III, Warszawa 1971, s. 34.

${ }^{6}$ Stownik współczesnego języka polskiego, red. B. Dunaj, Warszawa 1996, s. 932.

${ }^{7}$ A. Skrabacz, Ratownictwo III RP. Ogólna charakterystyka, Warszawa 2004.

${ }^{8}$ Z. Zamiar, Ratownictwo w systemie bezpieczeństwa, Wrocław 2013.

${ }^{9}$ Ustawa z dnia 18 sierpnia 2011 r. o bezpieczeństwie i ratownictwie w górach i na zorganizowanych terenach narciarskich (t.j. Dz. U. z 2019 r. poz. 1084), art. 2 pkt 7.

${ }^{10}$ Ustawa z dnia 18 sierpnia 2011 r. o bezpieczeństwie osób przebywających na obszarach wodnych(t.j. Dz. U. z 2018 r. poz. 1482 ze zm.), art. 2 pkt 4.

${ }^{11}$ Ustawa z dnia 24 sierpnia 1991 r. o ochronie przeciwpożarowej(t.j. Dz. U. z 2019 r. poz. 1372 ze zm.), art. 2 pkt 2.

${ }^{12}$ Ustawa z dnia 8 września 2006 r. o Państwowym Ratownictwie Medycznym(t.j. Dz. U. z 2019 r. poz. 993 ze zm.), art. pkt. 4 i 7.

${ }^{13}$ Ustawa z dnia 24 sierpnia 1991 r. o Państwowej Straży Pożarnej (t.j. Dz. U. z 2019 r. poz. 1499), art. 7 pkt 1.

14 Ibidem, pkt 2.

15 Vide: R. Radkowski, Działania ratownicze i ratowniczo-gaśnicze. Problematyka terminologii, „Zeszyty Naukowe SGSP” 2015, nr 55, s. 67-82.

${ }^{16}$ P. Gromek, Ratownictwo w ochronie ludności. Istota. System. Kierunki rozwoju, Warszawa 2015, s. 17.

17 Vide: R. Kalinowski, System ochrony i ratownictwa ludności [w:] Ochrona ludności w wymiarze wieloaspektowym, red. R. Kalinowski, P. Szmitkowski, S. Zakrzewska, Siedlce 2015, s. 43.
} 
i kategorii pojęciowych z tym bezpieczeństwem związanych (bezpieczeństwa powszechnego, ochrony ludności, a w konsekwencji do ratownictwa). W ścisłej relacji z wynikami rozważań na temat ratownictwa oraz $\mathrm{z}$ uwagi na stosunkowo wysoki stopień reprezentatywności teorii i koncepcji pierwotnych względem tych poniższych, warto przytoczyć następujące stanowiska:

- Kultura bezpieczeństwa jest związana z percepcją zagrożeń i sposobami postępowania w ich obliczu (A. Filipek) ${ }^{18}$;

- „Kultura bezpieczeństwa stanowi ogół utrwalonych, niematerialnych i materialnych elementów dorobku człowieka, które służą przewidywaniu, zapobieganiu, identyfikacji oraz pasywnej i aktywnej neutralizacji różnych zagrożeń bezpieczeństwa danego podmiotu" (J. Piwowarski) ${ }^{19}$;

- Kultura bezpieczeństwa jest utożsamiana ze wzorem podstawowych założeń, wartości, norm, reguł, symboli i przekonań, które są charakterystyczne dla danego podmiotu i wpływają na sposób postrzegania przez niego wyzwań, szans i/lub zagrożeń występujących w jego otoczeniu bliższym i dalszym. Kojarzy się ją również ze sposobem odczuwania bezpieczeństwa i myślenia o nim, w konsekwencji działalności w obliczu różnych układów czynników tę kulturę determinujących (M. Cieślarczyk, A. Filipek, A. W. Świderski, J. Ważniewska) ${ }^{20}$.

Zachowawczym jest założenie, że skoro ratownictwo jest związane z systemem działań ludzkich prowadzonych w charakterystycznych okolicznościach i na specyficznych zasadach, jest bardzo mocno związane z bezpieczeństwem (powszechnym, narodowym, państwa $\mathrm{i}$ in.), to sfera jego kultury koresponduje co do swojej struktury poznawczej z pojęciem kultury bezpieczeństwa. W konsekwencji poprzez kulturę ratownictwa można rozumieć wzorzec podstawowych założeń, wartości, norm, reguł, symboli i przekonań charakterystycznych dla podmiotów ratownictwa i wpływających na sposób postrzegania przez nie wyzwań, szans i/lub zagrożeń występujących $\mathrm{w}$ ich środowiskach wewnętrznych i otoczeniu, kojarzony ze sposobami myślenia o ratownictwie i właściwej działalności operacyjnej ukierunkowanej na ochronę ludzi, a także mienia i środowiska w zakresie niezbędnym do ich przeżycia w wymiarach biologicznym i bytowo-kulturowym, w okolicznościach lub w związku z okolicznościami reagowania na zagrożenia w trybie niezwłocznym (natychmiastowym, pilnym). Słowem uzupełnienia, mianem podmiotu ratownictwa określa się wszelkiego rodzaju byty zorganizowane (np. instytucje, systemy działań) oraz jednostkowe (jednostki ludzkie), które podejmują działania w przedmiotowym zakresie. Kultura ratownictwa zdaje się więc dotykać trudno mierzalnych obszarów analizowanej problematyki. Z tego powodu to właśnie

\footnotetext{
${ }^{18}$ Vide: A. Filipek, Niektóre tendencje zmian kultury bezpieczeństwa studentów w pierwszej i drugiej dekadzie XXI wieku [w:] Elementy teorii i praktyki transdyscyplinarnych badań problemów bezpieczeństwa. Bezpieczeństwo $i$ kultura bezpieczeństwa $w$ teorii, w badaniach naukowych $i$ w praktyce, red. A. Filipek, t. II, Siedlce 2014, s. 338-339 [za:] P. Gasparski, Psychologiczne wyznaczniki gotowości do zapobiegania zagrożeniom, Warszawa 2003.

${ }_{19}$ J. Piwowarski, Transdyscyplinarna istota kultury bezpieczeństwa narodowego, Słupsk 2016, s. 25.

${ }^{20}$ Vide: M. Cieślarczyk, A. Filipek, A. W. Świderski, J. Ważniewska, Istota kultury bezpieczeństwa i jej znaczenie dla człowieka i grup społecznych, „Kultura bezpieczeństwa” 2014, nr 1-2, s. 22-23.
} 
w niej upatrywany jest potencjał poznawczy umożliwiający poszukiwanie odpowiedzi na pytania o pobudki kierujące działalnością w zakresie ratownictwa i rzeczywiste sposoby realizacji właściwych zadań.

\section{Model IDEALNY KULTURY RATOWNiCTWA W POLSCE}

Z definicji kultury ratownictwa wynikają dwie płaszczyzny czynników ją determinujących:

- założenia, wartości, normy, reguły, symbole i przekonania eksponowane przez podmioty ratownictwa,

- $\quad$ wyzwania, szanse i zagrożenia widziane z perspektywy tychże podmiotów.

Zestawienie ze sobą wspomnianych dwóch płaszczyzn determinantów w relacji morfologicznej ${ }^{21}$ pozwala na identyfikację ciągu logicznego pojęć kształtujących idealny model kultury ratownictwa (bazujący na idealnym modelu kultury bezpieczeństwa M. Cieślarczyka). Są to wartości, normy, postawy, zachowania i działania.

Za L. Krzyżanowskim, wartości to ,wytwór odczuć, przeświadczeń lub przekonań jakiegoś podmiotu (...) o tym, co w rzeczywistości przyrodniczej i psycho-społeczno-kulturowej jest pozytywnie oceniane i uznawane za godne pożądania i dążeń" ${ }^{22}$. Poprzez wartości rozumie się atrybuty odpowiadania pragnieniom, oczekiwaniom, potrzebom i zdolnościom eksponującego je podmiotu, a także cechy, które uzasadniają przypisane temu podmiotowi powinności ${ }^{23}$. Mogą być one osiągane na rożne sposoby, przeważnie dzięki stosowaniu się do norm postępowania, czyli ustalonych, ogólnie przyjętych zasad działania ${ }^{24}$. Z norm, które niejako wyrastają na systemie wartości danego podmiotu, wynikają $\mathrm{z}$ kolei postawy pożądane $\mathrm{w}$ świetle okoliczności skutkujących zasadnością podejmowania działań o charakterze ratowniczym (lub szerzej, z zakresu ratownictwa) ${ }^{25}$.

Następny element ciągu logicznego pojęć charakteryzujących kulturę ratownictwa stanowią postawy. Zgodnie ze stanowiskiem M. Cieślarczyka są one konstytuowane przez komponent racjonalny (związany z wiedzą i sposobami myślenia), komponent emocjonalny oraz komponent behawioralny (utożsamiany z gotowością do podejmowania określonych działań). Same działania to odmiana zachowań. Te pierwsze wyróżniają się na tle tych drugich intencjonalnością i sensownością podejmowanej aktywności ${ }^{26}$. Nadmienia się, że w kontekście ratownictwa pożądana jest szczególna forma działalności, jaką jest współdziałanie (a zwłaszcza współpraca),

\footnotetext{
21 Vide: A. Ujwary-Gil, Wykorzystanie analizy morfologicznej w poszukiwaniu nowej formy reklamowania produktu, Marketing i Rynek 2003, nr 6, s. 2; T. Ritchey, Fritz Zwicky, Morphologie and Policy Analysis, FOA 1998.

${ }^{22}$ Vide: L. Krzyżanowski, Podstawy nauk o organizacji i zarzadzaniu, Warszawa 1992, s. 143.

${ }^{23}$ Vide: H. Elzenberg, Pojęcie wartości perfekcyjnej [w:] Pisma aksjologiczne, Lublin 2002, s. 97-99.

${ }^{24}$ Vide: Uniwersalny stownik języka polskiego, red. S. Dubisz, t. 2, Warszawa 2003, s. 1018; M. Cieślarczyk, A. Filipek, A. W. Świderski, J. Ważniewska, Istota kultury..., s. 26.

${ }^{25}$ Autor stoi na stanowisku, że działalność z zakresu ratownictwa można podzielić na działania o charakterze zarządczym (działania kierownicze) oraz działania o charakterze wykonawczym (ratownicze, ratunkowe). Założenie to pozwala uporządkować instrumentarium definicyjne teorii i praktyki ratownictwa w Polsce.

${ }^{26}$ Vide: M. Cieślarczyk, Kultura bezpieczeństwa i bezpieczeństwo kulturowe [w:] Współczesne bezpieczeństwo i kultura bezpieczeństwa, red. A. Filipek, B. Gałek, Siedlce 2014, s. 21-22.
} 
definiowane przez B. Wiśniewskiego jako ,wspólne działanie lub udzielanie pomocy w realizacji zadań związanych z osiągnięciem precyzyjnie określonego, wymiernego celu, związanego z pełną realizacją przedsięwzięć dotyczących realizacji zadań na rzecz bezpieczeństwa"27. Jest ono kluczowe szczególnie wtedy, gdy wynika z uświadomienia sobie pewnych braków (zasobów ludzkich, rzeczowych, informacyjnych i/lub finansowych) w aspekcie realizacji wyznaczonego celu $^{28}$.

Wzajemne zależności występujące pomiędzy elementami ciągu logicznego pojęć kształtujących idealny model kultury ratownictwa w odniesieniu do poszczególnych jego dziedzin zobrazowano na rysunku 1.

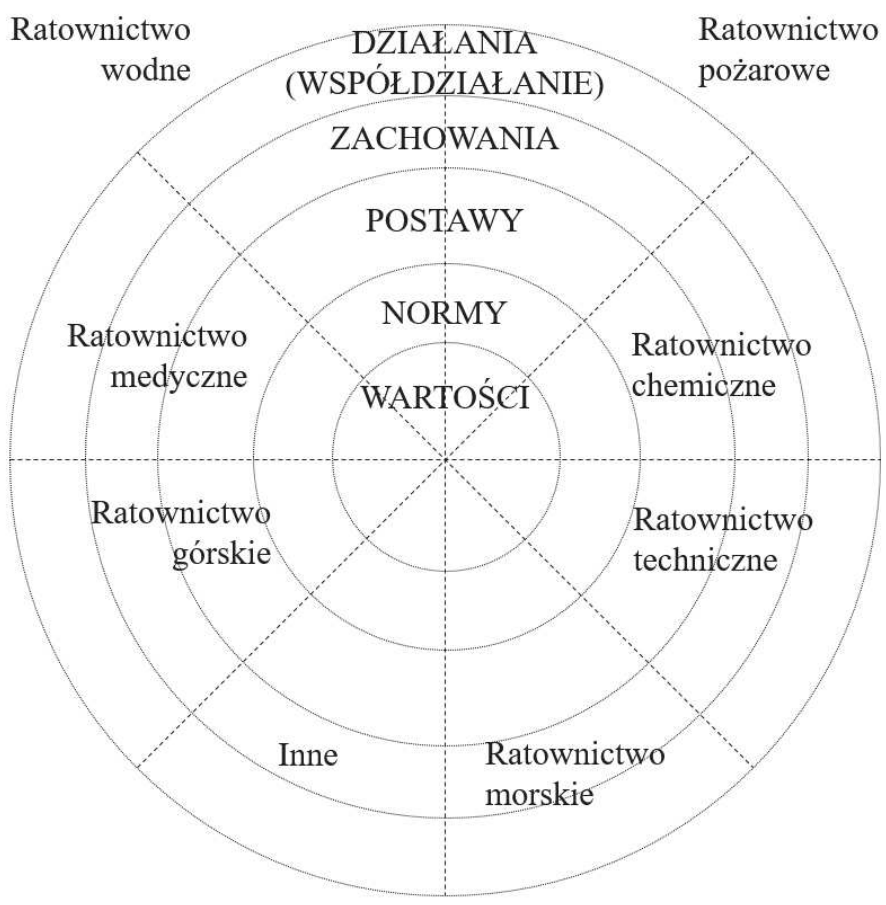

Rysunek 1. Model idealny kultury ratownictwa

Źródło: opracowanie własne na podstawie: M. Cieślarczyk, Teoretyczne i metodologiczne podstawy badania problemów bezpieczeństwa i obronności państwa, Siedlce 2009, s. 160.

Nie bez powodu zdywersyfikowano domenę działalności w zakresie ratownictwa ze względu na właściwe dziedziny (ratownictwo pożarowe, ratownictwo wodne, ratownictwo górskie itd.). Podkreślana przez A. Skrabacz jego branżowość (czy też resortowość) ma zasadniczy wpływ na wymiar kulturowy ${ }^{29}$. Zróżnicowanie podstaw normatywnych, zasad funkcjonowania poszczególnych podmiotów i sposobów postrzegania zagrożeń oddziałujących na życie i zdrowie ludzkie, a także mienie i środowisko w stosownym zakresie jedynie utwierdzają w tym przekonaniu. Chcąc uzyskać całościowy obraz kultury ratownictwa, należy wziąć pod uwagę wszystkie jego rodzaje.

\footnotetext{
${ }^{27}$ B. Wiśniewski, System bezpieczeństwa państwa. Konteksty teoretyczne i praktyczne, Szczytno 2013, s. 298.

${ }^{28}$ Vide:J. Prońko, Bezpieczeństwo państwa. Zarys teorii problemu i zadań administracji publicznej, Bielsko Biała 2007, s. 66

${ }^{29}$ Vide: A. Skrabacz, op. cit., s. 12.
} 


\section{Ogólne uWARUnKowania Kultury Ratownictwa W Polsce}

Podstawowym założeniem analizy ogólnych uwarunkowań kultury ratownictwa w Polsce jest to, że omawiane zagadnienie nierozerwalnie wiąże się z podmiotem, o którego kulturę chodzi. Na najwyższym poziomie ogólności można mówić o takich podmiotach ratownictwa, jak:

- obywatele i inne osoby przebywające na terytorium kraju prowadzące działania w zakresie ratownictwa (podmioty jednostkowe),

- instytucje ratownictwa (PSP, organy administracji publicznej pełniące funkcje podmiotów zarządzania kryzysowego, ochotnicze straże pożarne - OSP, Górskie Ochotnicze Pogotowie Ratunkowe - GOPR, itp.),

- systemy działań w zakresie ratownictwa (od tych sformalizowanych - m. in. KSRG, systemu Państwowe Ratownictwo Medyczne, czyli systemu PRM, systemu powiadamiania ratunkowego przez ich niesformalizowane odpowiedniki, np. system ratownictwa górniczego, system ratownictwa morskiego, po upodmiotowiony, holistyczny system ratownictwa, który konceptualnie obejmuje wszystkie wymienione, jednostkowe, instytucjonalne i systemowe podmioty ratownictwa $)^{30}$.

W teorii i praktyce ratownictwa nawiązuje się do najważniejszych wartości utylitarnych - ludzkiego życia i zdrowia (a także mienia i środowiska, aczkolwiek tylko w zakresie niezbędnym do przeżycia ludności w wymiarach biologicznym i bytowo-kulturowym). Rezultat ich dekompozycji na wartości elementarne jest ściśle powiązany z okolicznościami działalności w zakresie ratownictwa. Kwestia ta zdaje się najbardziej uporządkowana w przypadku instytucji ratownictwa i tworzonych przez nie systemów działań, ponieważ zostały one wręcz stworzone do ochrony wspomnianych wartości utylitarnych. Jest to zdecydowanie bardziej złożone w przypadku podmiotów jednostkowych. „W sytuacji ryzyka poniekąd ujawnia się rzeczywisty porządek wartości podmiotu, jako że wówczas szczególnie uwidacznia się to, co tak naprawdę jest dla niego najbardziej cenne" ${ }^{\text {,31 }}$. Nie zawsze jednak jest to życie i zdrowie drugiego człowieka.

Niektóre podmioty ratownictwa wypracowały właściwe sobie normy postępowania, wpisując je w dokumenty normatywne i/lub kodeksy etyczne. Za przykłady niech posłużą chociażby Zasady etyki zawodowej funkcjonariuszy Państwowej Straży Pożarnej ${ }^{32}$, Kodeks etyki zawodowej ratownika medycznego ${ }^{33}$ oraz szablonowy projekt statutu ochotniczej straży pożarnej $^{34}$. Różnią się względem siebie co do zakresu, struktury i poziomu szczegółowości zawartych regulacji. Warto nadmienić, że część wspomnianych podmiotów nie ma spisanych

\footnotetext{
30 Teoria holistycznego systemu ratownictwa (nazywanego w literaturze przedmiotu krajowym systemem ratowniczym lub polskim systemem ratownictwa) traktuje o systemie systemów i instytucji ratownictwa, czyli bycie zorganizowanym w oparciu wszystkie podmioty prowadzące działalność w zakresie ratownictwa.

${ }^{31}$ Z. Spendel, Ryzyko a wartości. Aksjologiczny wymiar podejmowania ryzyka [w:] Zachowanie się w sytuacji ryzyka, red. R. Studenski, Katowice 2004, s. 41.

${ }^{32}$ Komenda Główna PSP, Warszawa.

${ }^{33}$ Polska Rada Ratowników Medycznych, Kraków 2013.

${ }^{34} \mathrm{http}: / / w w w . z o s p r p . p l / f i l e s /$ Statut\%20OSP.doc (13.10.2019).
} 
norm postępowania. Stosuje się je nieformalnie. Są kojarzone przeważnie z etosem ratownika (np. morskiego, górniczego), a także społecznymi wymaganiami osadzonymi w branżowym i społecznym postrzeganiem osób pełniących tę rolę.

Wspomniane normy stanowią fundament, na którym wyrastają postawy i zachowania podmiotów ratownictwa w obliczu zagrożeń bezpieczeństwa powszechnego. Ich sformalizowanie lub przynajmniej nieformalne określenie sprzyja przewidywalności co do behawioralnej odpowiedzi ratowników zawodowych i/lub ochotników w konkretnych okolicznościach reagowania na pożary, powodzie, zagrożenia chemiczne, wypadki na morzu, tąpnięcia w kopalni itd. Zakłada się, że postawy i zachowania wyrażane przez przedstawicieli instytucji ratownictwa są właściwe odpowiadającym im systemom działań (np. PSP, OSP i inne wybrane jednostki ochrony przeciwpożarowej - KSRG). W dokumentach regulujących zasady ich funkcjonowania można odnaleźć szczegółowe wykazy działań i zakresów współdziałania dotyczące ratownictwa.

Zdecydowanie bardziej złożony problem dotyka w niniejszym świetle podmiotów jednostkowych. Ich postawy, zachowania i działania (w tym współdziałanie) mogą być w znacznej mierze pochodną takich czynników, jak m. in. ${ }^{35}$ :

- wiek,

- pochodzenie etniczne,

- język,

- posiadane wykształcenie,

- emocje wyzwalane w związku z wystąpieniem zagrożenia,

- emocje towarzyszące partycypowaniu w działaniach ratowniczych (satysfakcja, bezsilność, stres, zmęczenie, strach, smutek itp.),

- zdolność detekcji, percepcji oraz interpretacji zdarzenia uważanego za niekorzystne z perspektywy bezpieczeństwa powszechnego,

- otwartość na współdziałanie (interwencyjne),

- otwartość na współdziałanie (komunikacja),

- wzajemne zrozumienie ratujących i ratowanych,

- odporność psychiczna,

- potrzeba wsparcia psychicznego,

- wyuczone lub podświadome wzorce behawioralne (współdziałanie, spokój, poszukiwanie informacji, chęć ucieczki, agresywność, próby ratowania mienia),

- świadomość istotności wpływu czynników kulturowych na efektywność działań ratowniczych.

Istnieje duży rozdźwięk pomiędzy zastaną rzeczywistością, a rzeczywistością pożądaną, Teoretycznie bowiem rzecz ujmując, w Polsce żyje około 30 milionów potencjalnych

\footnotetext{
${ }^{35}$ Vide: Z. Baskaya Sofuoglu, T. Sofuoglu, E. Yildirim, D. Kehl, Human behaviour and culture in emergency situations [w:] Behaviour - Security - Culture. Human behavior in emergencies and disasters: A cross-cultural investigation, red. S. Schmidt, E. Galea, Lengerich 2013, s. 37-44.
} 
ratowników. To osoby zobligowane i z założenia zdolne do przestrzegania prawa krajowego, którego treści nakładają obowiązek:

- udzielenia pomocy człowiekowi znajdującemu się w położeniu grożącym bezpośrednim niebezpieczeństwem utraty życia albo ciężkiego uszczerbku na zdrowiu, o ile nie narazi się tym siebie lub innej osoby na niebezpieczeństwo utraty życia albo ciężkiego uszczerbku na zdrowiu ${ }^{36}$,

- powiadomienia lub przynajmniej przyczynienia się do powiadomienia podmiotów ustawowo powołanych do niesienia pomocy osobom w stanie nagłego zagrożenia zdrowotnego po zauważeniu osoby lub osób znajdujących się w takim stanie, bądź o fakcie bycia świadkiem zdarzenia powodującego taki $\operatorname{stan}^{37}$,

- udzielenia przez kierującego pojazdem niezbędnej pomocy ofiarom wypadku oraz wezwania zespołu ratownictwa medycznego i Policji w okolicznościach, w których są osoby zabite i/lub ranne ${ }^{38}$,

- $\quad$ informowania o zagrożeniach występujących na obszarach wodnych oraz w górach ${ }^{39}$.

Doniesienia medialne pokazują jednak, że ludzie nie chcą i/lub boją się udzielać pomocy o charakterze ratowniczym ${ }^{40}$. Rzuca to światło na stan kultury ratownictwa w Polsce, zwłaszcza w odniesieniu do społecznego komponentu ratownictwa. $\mathrm{Z}$ tego powodu bardzo trudno określić stopień i zakres partycypacji jednostek ludzkich (obywateli i innych osób przebywających na terenie kraju) w działaniach ratowniczych, wskazując liczne kierunki dla pogłębionej eksploracji naukowej w formie dociekań teoretycznych i badań empirycznych ${ }^{41}$.

\section{PodsumoWANIE}

Kultura bezpieczeństwa stanowi zagadnienie o wysokim potencjale badawczym. Można o niej traktować zarówno jako o przedmiocie poznania, jak i o względzie poznawczym. Właściwe teorie naukowe i działalność praktyczna stwarzają możliwości do poszukiwania odpowiedzi na pytania o trudno mierzalne aspekty rzeczywistości. Z tego powodu przedmiotowy dorobek znajduje zastosowanie w badaniach nad szeroko rozumianym ratownictwem, czyli dziedziną bezpieczeństwa powszechnego oznaczającą działalność operacyjną na wszystkich poziomach zarządzania bezpieczeństwem państwa, we wszystkich stanach jego funkcjonowania, ukierunkowaną na ochronę ludzi, a także mienia i środowiska w zakresie niezbędnym do ich przeżycia w wymiarach

\footnotetext{
${ }^{36}$ Ustawa z dnia 6 czerwca 1997 r. Kodeks karny (t.j. Dz. U. z 2018 r. poz. 1600, ze zm.), art. 162 § 2.

${ }^{37}$ Ustawa z dnia 8 września 2006 r. o Państwowym Ratownictwie Medycznym(t.j. Dz. U. z 2019 r. poz. 993 ze zm.), art. 4.

${ }^{38}$ Ustawa z dnia 20 czerwca 1997 r. Prawo o ruchu drogowym (t.j. Dz. U. z 2018 r. poz. 1990 ze zm.), art. 3.

${ }^{39}$ Ustawa o bezpieczeństwie osób przebywających na obszarach wodnych...,art. 3 oraz ustawa o bezpieczeństwie i ratownictwie w górach..., art. 4.

$40 \quad$ http://rzeszow.tvp.pl/42836137/nie-udzielili-pomocy-rannemu-motocykliscie-zlamali-prawo (13.10.2019), $\mathrm{http}: / /$ motoryzacja.interia.pl/wiadomosci/polski-kierowca/news-ty-tez-nie-udzielisz-pomocy,nId,2548244 (13.10.2019).

${ }^{41}$ Vide: P. Gromek, W sieci ratownictwa, Warszawa 2018, s. 195-217.
} 
biologicznym i bytowo-kulturowym, w okolicznościach lub w związku z okolicznościami reagowania na zagrożenia w trybie niezwłocznym (natychmiastowym, pilnym).

Czerpiąc z rezultatów dotychczasowych badań naukowych, kulturę ratownictwa można zdefiniować jako wzorzec podstawowych założeń, wartości, norm, reguł, symboli i przekonań charakterystycznych dla podmiotów ratownictwa i wpływających na sposób postrzegania przez nie wyzwań, szans i/lub zagrożeń występujących w ich środowiskach wewnętrznych i otoczeniu, kojarzony ze sposobami myślenia o ratownictwie i właściwej działalności.

Do zrozumienia ogólnych uwarunkowań kultury ratownictwa w Polsce konieczne jest skupienie się na elementach logicznego ciągu pojęć: wartości, normy, postawy, zachowania i działania, ze zwróceniem uwagi na szczególną odmianę działań, jaką jest współdziałanie (tu współdziałanie w zakresie ratownictwa). Naniesienie ich struktury (w sensie elementów i łączących je relacji) na pełną domenę działalności w zakresie ratownictwa ukazaną w podziale branżowym pozwala zbudować model idealny, a równocześnie wstępną strukturę poznania omawianej problematyki.

Specyfika działalności w zakresie ratownictwa znajduje swoje odzwierciedlenie w postrzeganiu elementów modelu idealnego kultury ratownictwa oraz zależności występujących między jego elementami. Wpływa tym samym na sposób rozumienia ogólnych uwarunkowań kultury ratownictwa w Polsce. Już wstępne wyniki dociekań teoretycznych skłaniają ku przekonaniu o słuszności kontynuacji badań naukowych w tym zakresie. Dysonans towarzyszący odniesieniu regulacji prawnych do rzeczywistego stopnia otwartości obywateli na prowadzenie działalności ratowniczej to jeden z zasadniczych powodów potwierdzających to założenie.

\section{BibliografiA}

Baskaya Sofuoglu Zeynep, Sofuoglu Turhan, Yildirim Elif, Kehl Doris. 2013. Human behaviour and culture in emergency situations. W Behaviour - Security - Culture. Human behavior in emergencies and disasters: A cross-cultural investigation, 3245.Pabst Science Publishers.

Cieślarczyk Marian, Filipek Agnieszka, Świderski Andrzej, Ważniewska Joanna. 2014. „Istota kultury bezpieczeństwa i jej znaczenie dla człowieka i grup społecznych”. Kultura bezpieczeństwa Nr 1-2 : 17-57.

Cieślarczyk Marian. 2014. Kultura bezpieczeństwa i bezpieczeństwo kulturowe. W Współczesne bezpieczeństwo i kultura bezpieczeństwa, 16-29. Wydawnictwo Uniwersytetu Przyrodniczo-Humanistycznego w Siedlcach.

Elzenberg Henryk. 2002. Pisma aksjologiczne. Lublin: Wydawnictwo Uniwersytetu Marii Curie-Skłodowskiej.

Filipek Agnieszka. 2014. Niektóre tendencje zmian kultury bezpieczeństwa studentów w pierwszej i drugiej dekadzie XXI wieku. W Elementy teorii i praktyki transdyscyplinarnych badań problemów bezpieczeństwa. Bezpieczeństwo i kultura bezpieczeństwa w teorii, w badaniach naukowych i w praktyce, 337-351. Wydawnictwo Uniwersytetu PrzyrodniczoHumanistycznego w Siedlcach. 
Gasparski Piotr. 2003. Psychologiczne wyznaczniki gotowości do zapobiegania zagrożeniom. Warszawa: Wydawnictwo Instytutu Psychologii Polskiej Akademii Nauk.

Gromek Paweł. 2015. Ratownictwo w ochronie ludności. Istota. System. Kierunki rozwoju. Warszawa: Wydawnictwo Szkoły Głównej Służby Pożarniczej.

Gromek Paweł. 2017. Teoria organizacji bezpieczeństwa na przykładzie masowej ewakuacji ludności. Warszawa: Difin.

Gromek Paweł. 2018. W sieci ratownictwa. Warszawa: Wydawnictwo Szkoły Głównej Służby Pożarniczej.

Kalinowski Romuald. 2015. System ochrony i ratownictwa ludności. W Ochrona ludności w wymiarze wieloaspektowym, 39-53. Wydawnictwo Uniwersytetu PrzyrodniczoHumanistycznego w Siedlcach.

motoryzacja.interia.pl.

Praca zbiorowa. 2013. Kodeks etyki zawodowej ratownika medycznego. Kraków: Polska Rada Ratowników Medycznych.

Krzyżanowski Leszek. 1992. Podstawy nauk o organizacji i zarządzaniu. Warszawa: Wydawnictwo Naukowe PWN.

Praca zbiorowa. 1971. Mała encyklopedia wojskowa t. III. Warszawa: Wydawnictwo Ministerstwa Obrony Narodowej.

Piwowarski Juliusz. 2016. Transdyscyplinarna istota kultury bezpieczeństwa narodowego.

Słupsk: Stowarzyszenie Edukacja i Wychowanie dla Pokoleń -Wydawnictwo Naukowe Akademii Pomorskiej.

Prońko Jarosław. 2007. Bezpieczeństwo państwa. Zarys teorii problemu i zadań administracji publicznej. Bielsko Biała: Wydawnictwo Wyższej Szkoły Administracji w Bielsku Białej.

Radkowski Radosław. 2015. „Działania ratownicze i ratowniczo-gaśnicze. Problematyka terminologii". Zeszyty Naukowe SGSP Nr 55 : 67-82.

Ritchey Tom. 1998. Fritz Zwicky, Morphologie and Policy Analysis. FOA.

Skrabacz Aleksandra. 2004. Ratownictwo III RP. Ogólna charakterystyka. Warszawa: Wydawnictwo Akademii Obrony Narodowej.

Praca zbiorowa. Słownik współczesnego języka polskiego. Warszawa: Wydawnictwo Wilga 1996.

Spendel Zbigniew. 2004. Ryzyko a wartości. Aksjologiczny wymiar podejmowania ryzyka. W Zachowanie się w sytuacji ryzyka, 35-43, Wydawnictwo Uniwersytetu Śląskiego.

Ujwary-Gil Anna. 2003. „Wykorzystanie analizy morfologicznej w poszukiwaniu nowej formy reklamowania produktu". Marketing i Rynek Nr 6 : 2-6.

Praca zbiorowa. 2003. Uniwersalny słownik języka polskiego t. 2. Warszawa: Wydawnictwo Naukowe PWN.

Ustawa $\mathrm{z}$ dnia 18 sierpnia 2011 r. o bezpieczeństwie i ratownictwie $\mathrm{w}$ górach i na zorganizowanych terenach narciarskich (t.j. Dz. U. z 2019 r. poz. 1084).

Ustawa z dnia 18 sierpnia 2011 r. o bezpieczeństwie osób przebywających na obszarach wodnych (t.j. Dz. U. z 2018 r. poz. 1482 ze zm.).

Ustawa z dnia 20 czerwca 1997 r. Prawo o ruchu drogowym (t.j. Dz. U. z 2018 r. poz. 1990 ze $\mathrm{zm}$.).

Ustawa z dnia 24 sierpnia 1991 r. o ochronie przeciwpożarowej (t.j. Dz. U. z 2019 r. poz. 1372 ze $\mathrm{zm}$.). 
Ustawa z dnia 24 sierpnia 1991 r. o Państwowej Straży Pożarnej (t.j. Dz. U. z 2019 r. poz. 1499).

Ustawa z dnia 6 czerwca 1997 r. Kodeks karny (t.j. Dz. U. z 2018 r. poz. 1600, ze zm.).

Ustawa z dnia 8 września 2006 r. o Państwowym Ratownictwie Medycznym (t.j. Dz. U. z 2019 r. poz. 993 ze zm.).

Wiśniewski Bernard. 2013. System bezpieczeństwa państwa. Konteksty teoretyczne i praktyczne. Szczytno: Wydawnictwo Wyższej Szkoły Policji w Szczytnie.

Wolanin Jerzy. 2005. Zarys teorii bezpieczeństwa obywateli. Ochrona ludności na czas pokoju. Warszawa: Danmar.

wroclaw.eska.pl.

zosprp.pl.

Zamiar Zenon. 2013. Ratownictwo w systemie bezpieczeństwa. Wrocław: Wydawnictwo Uczelniane Wyższej Szkoły Oficerskiej Wojsk Lądowych imienia generała Tadeusza Kościuszki.

Praca zbiorowa. Zasady etyki zawodowej funkcjonariuszy Państwowej Straży Pożarnej. Warszawa: Komenda Główna Państwowej Straży Pożarnej. 